\title{
A proteção internacional do patrimônio cultural ${ }^{*}$
}

\author{
James L. Bischoff ${ }^{\star *}$
}

\section{INTRODUÇÃO}

\section{A) A ameaça ao patrimônio cultural}

A Convenção da UNIDROIT sobre Bens Culturais Furtados ou Ilicitamente Exportados de 1995, o mais atual dos acordos multilaterais que abrangem o tema do patrimônio cultural, apresenta a seguinte definição de "bens culturais": "Entende-se como bens culturais... aqueles bens que, a título religioso ou profano, se revestem (sic) de uma importância para a arqueologia, a pré-história, a história, a literatura, a arte ou a ciência...." O conceito

\footnotetext{
* Trabalho apresentado na disciplina Direito das Relações Internacionais, ministrada pela professora doutora Cláudia Lima Marques, no Curso de Graduação em Ciências Jurídicas e Sociais da Faculdade de Direito da Universidade Federal do Rio Grande do Sul.

** Aluno do Convênio CAPES/FIPSE entre a Universidade Federal do Rio Grande do Sul e a University of Texas at Austin, durante os meses de janeiro a agosto de 2003. Estudante de Direito (J.D.) da University of Texas School of Law e Mestrando (M.A.) em Estudos LatinoAmericanos pela University of Texas Lozano Long Institute of Latin American Studies (LLILAS). Formado em História e Letras Hispânicas pela University of Kentucky. O autor agradece à professora doutora Cláudia Lima Marques, pela colaboração na publicação do presente artigo, e à acadêmica de Direito da UFRGS, Antonia Espíndola Longoni Klee, pelas sugestões lingüísticas e revisão do texto.
}

1 Convenção da UNIDROIT sobre Bens Culturais Furtados ou Ilicitamente Exportados, celebrada em Roma, no dia 24 de junho de 1995, art. $2^{\circ}$ [daqui para diante UNIDROIT 1995]. A Convenção da UNIDROIT foi aprovada no Brasil pelo Decreto Legislativo n. 4, de 21 de janeiro de 1999; foi promulgada, com o texto integral em português, pelo Decreto n. 3.116, de 14 de setembro de 1999. Vide também Stephanie O. Forbes, Securing the Future of Our Past: Current Efforts to Protect Cultural Property, 9 TranSNAT'L LaW 235, 239-40 (1996). 
do patrimônio cultural, então, é bastante extenso: inclui não somente a arte, os artefatos e as antigüidades, mas também os monumentos e edifícios históricos, as ruínas e os navios naufragados, os objetos e locais religiosos e os artefatos contemporâneos de povos indígenas. ${ }^{2}$

Há inumeráveis razões para se proteger e se preservar o patrimônio cultural. Por um lado, algumas expressões culturais, especialmente os monumentos e outras edificações, têm grande valor como depositários do conhecimento e testemunhos da experiência humana; o patrimônio cultural é um retrato da origem e da evolução humana. Por outro lado, o patrimônio cultural tem valor pelo que expressa em termos estéticos, históricos e religiosos; isto é, possui uma importância intrínseca, pois a sua existência nos dá satisfação. Outrossim, os bens culturais que pertencem a um grupo em particular fomentam a sua dignidade, uma vez que promovem a auto-identificação e a autocompreensão; ajudam-lhe a definir a sua singularidade como povo e, para alguns grupos étnicos, são garantidores de força e segurança. ${ }^{3}$

Entretanto, apesar do enriquecimento de nossa vida coletiva que provém da proteção e da preservação dos bens culturais, a segurança e a integridade de tais bens têm sido continuamente comprometidas por diversas atividades humanas. A mais destrutiva não deve surpreender: a guerra tem sido responsável por uma quantidade incalculável de perdas de bens culturais, estes últimos sendo vítimas tanto de incursões e bombardeios, quanto da pilhagem que sempre acompanha os ambientes de conflito e

2 O patrimônio cultural brasileiro, de acordo com a Constituição de 1988, é constituído pelos "bens de natureza material e imaterial, tomados individualmente ou em conjunto, portadores de referência à identidade, à ação, à memória dos diferentes grupos da sociedade brasileira, nos quais se incluem: $a$ ) as formas de expressão; $b$ ) os modos de criar, fazer e viver; $c$ ) as criações científicas; $d$ ) as obras, objetos, documentos, edificações e demais espaços destinados às manifestações artístico-culturais; $e$ ) os conjuntos urbanos e sítios de valor histórico, paisagístico, artístico, arqueológico, paleontológico, ecológico e científico." Constituição Federal da República Federativa do Brasil, promulgada em 5 de outubro de 1988, art. 216. Vide também Helli Alves de Oliveira, Responsabilidade pelos danos ao patrimônio cultural, REVISTA FORENSE, vOL.49, p. 319 (1992), para informação geral sobre o regime brasileiro de proteção do patrimônio cultural.

3 Por exemplo, a escultura Afo-A-Kom, de uma tribo da República de Camarões, dá força e segurança à tribo, mas só quando está fisicamente presente. Vide infra, nota 98 . Vide também Lakshman Guruswamy, Jason C. Roberts and Catina Drywater, Protecting the Cultural and Natural Heritage: Finding Common Ground, 34 TULSA L.J. 713, 716-17 (1999). 
desordem. ${ }^{4}$ Outra formidável atividade que ameaça a segurança do patrimônio cultural é economicamente motivada: o tráfico dos bens culturais furtados ou ilicitamente exportados constitui uma das indústrias mais lucrativas do mundo. ${ }^{5}$ Dentre os protagonistas deste comércio, figuram os seguintes sujeitos: os inescrupulosos e avarentos comerciantes de arte; os colecionadores e os museus nos países importadores, que muitas vezes não sabem do status ilícito dos bens; os "soldados de fortuna" (huaqueros), que violam sítios arqueológicos à procura de algo vendável; e os paupérrimos e desesperados habitantes dos "países fontes", que se submetem a vender os seus tesouros culturais a preços vergonhosamente baixos. ${ }^{6}$ Tanto o comércio desenfreado dos bens culturais, como $o$ aniquilamento ou pilhagem na guerra, privam-nos de uma parte essencial de nossa existência humana e destroem dados científicos do nosso passado comum.

\section{B) A estrutura do artigo}

Para combater a destruição, a deterioração e a descontextualização dos bens culturais, a comunidade internacional tem construído uma variedade de mecanismos jurídicos que buscam criar uma ampla rede de proteção para o patrimônio cultural. A Parte II expõe os principais instrumentos do direito internacional que tratam da salvaguarda dos bens culturais: a Parte II (A) delineia o desenvolvimento histórico das normas protetoras aplicáveis durante a guerra, e a Parte II (B) discute os aspectos centrais do regime criado para tempos de paz. As Partes III e IV abordam, respectivamente, as principais fraquezas da atual rede de instrumentos de proteção e algumas idéias recentemente propostas para o seu melhoramento.

4 Vide, e.g., Joanne Mariner, Liberation and Looting in Iraq, FINDLAW's LEGAL COMMENTARY, Apr. 14, 2003, em http://writ.news.findlaw.com/mariner/20030414.html.

5 Vide Forbes, supra nota 3, p. 238. Vide também Jennifer H. Lehman, The Continued Struggle with Stolen Cultural Property: The Hague Convention, the UNESCO Convention, and the UNIDROIT Draft Convention, 14 ARIZ. J. INT'L \& Comp. L. 527, 528 (1997).

6 Por exemplo, o mercado privado obviamente teve poder o bastante para incentivar os camponeses comuns do Mali a colher e vender quase todas as terracotas preciosas do país. Estas terracotas atualmente formam parte de várias coleções européias, perdendo-se assim o contexto cultural das peças, em conjunto com qualquer oportunidade da grande maioria dos descendentes dos autores das obras de desfrutar daquela parte do seu patrimônio histórico. Vide Lehman, supra nota 7, p. 529. 


\section{O MARCO JURÍDICO INTERNACIONAL PARA A PROTEÇÃO DO PATRIMÔNIO CULTURAL}

A) O desenvolvimento histórico da proibição de danos ao patrimônio cultural durante tempos de guerra

1. O desenvolvimento até a Segunda Guerra

a) A regra antiga: pilhagem permitida

Através da História, a pilhagem indiscriminada e sistemática de obras de arte vinculava-se inextricavelmente ao conceito da guerra; a exibição pública dos "troféus" saqueados de povos vencidos já se tinha tornado um costume para os romanos no transcurso do século IV a.C. Além disso, alguns conflitos armados tiveram como motivo singular a aquisição de bens culturais; por exemplo, o ataque contra Praga, ordenado pela Rainha Cristina da Suíça, em 1648, teve como propósito a captura da coleção de arte do Imperador Rodolfo. ${ }^{7}$

\section{b) A mudança da atitude internacional quanto à pilha- gem durante o século XIX}

Logo no princípio do século XIX, porém, a atitude internacional quanto a certos atos de pilhagem dos bens culturais na guerra começou a mudar. Uma característica notória das campanhas napoleônicas foi a apropriação dos bens culturais dos povos europeus vencidos, a fim de enriquecer o novo Musée Napoléon (hoje Musée du Louvre) em Paris; os termos nos acordos de paz assinados por Napoleão sempre incluíam a entrega de obras de arte para a França, uma prática considerada particularmente insultante e ofensiva pelas vítimas. ${ }^{8}$ Quando as Forças Aliadas lograram vencer Napoleão, ordenaram a repatriação (parcial, pelo menos) dos bens apropriados pelos franceses. Durante a mesma época, surgiu um longo e vigoroso debate na Europa, sobre a legalidade e a moralidade da remoção dos chamados "Mármores de Elgin" e sua subseqüente compra pelo Governo inglês. Os Mármores, originalmente pertencentes à Acrópole de Antenas e que por séculos estavam sob o controle do Império Otomano, tinham sido apropriados pelo militar inglês Lorde Elgin. ${ }^{9}$

O segundo período de prolongada discussão internacional sobre a permissão do saque e dos danos ao patrimônio cultural durante a guerra iniciouse na Guerra de Secessão NorteAmericana, com o afamado Código

7 Victoria A. Birov, Prize or Plunder?: The Pillage of Works of Art and the International Law of War, 30 N.Y.U. J. INT'L L. \& PoL. 201, 205 (1997-98).

8 Id. pp. 205-06.

9 John Henry Merryman, The Free International Movement of Cultural Property, 31 N.Y.U. J. INT'L L. \& PoL. 1, 1-2 (1998) [daqui para diante Merryman Free Movement]. 
Lieber de $1863 .{ }^{10}$ O Código, que visava a regular o comportamento das tropas americanas nas suas campanhas militares, contém três artigos que são a gênese do direito internacional humanitário sobre o patrimônio cultural;" $\mathrm{o}$ artigo 35 é o mais ilustrativo deles, proporcionando um status de proteção às obras de arte e às bibliotecas: " $A s$ clássicas obras de arte, as bibliotecas, as coleções científicas ou instrumentos precisos - tais como os telescópios astronômicos -, assim como hospitais, devem ser assegurados contra todos os danos evitáveis, mesmo quando dentro de locais fortificados durante o sitio ou bombardeio."
Os três artigos do Código Lieber serviram como base para a ulterior codificação do direito da guerra, inclusive das regras protetivas dos bens culturais. Assim, o Código é considerado a inspiração jurídica dos Regulamentos de Haia de 1907 e da Convenção de Haia de $1954 .^{12}$

c) O desenvolvimento da
proteção no século $X X$ até a Segunda Guerra

Os Regulamentos de Haia de 1907 contêm as principais regras internacionais sobre o patrimônio cultural do período antes da promulgação da Convenção de $1954 .{ }^{13}$ Um congresso

10 John Henry Merryman, Two Ways of Thinking About Cultural Property, 80 AM. J. INT'L L. 831, 833 (1986) [daqui para diante Merryman Two Ways].

11 Francis Lieber, Instructions for the Government of Armies of the United States in the Field, reimpressa em The Miscellaneous Writings OF Francis Lieber 247 [daqui para diante Código Lieber], arts. 34-36. O texto dos artigos 34-36 aparece a seguir: Art. 34: "As a general rule, the property belonging to churches, to hospitals, or other establishments of an exclusively charitable character, to establishments of education, or foundations for the promotion of knowledge, whether public schools, universities, academies of learning or observatories, museums of the fine arts, or of a scientific character - such property is not to be considered public property ... but it may be taxed or used when the public service may require it." Art. 35: "Classical works of art, libraries, scientific collections, or precise instruments, such as astronomical telescopes, as well as hospitals, must be secured against all avoidable injury, even when they are contained in fortified places whilst besieged or bombarded." Art. 36: "If such works of art, libraries, collections, or instruments belonging to a hostile nation or government can be removed without injury, the ruler of the conquering state or nation may order them to be seized and removed for the benefit of the said nation. The ultimate ownership is to be settled by the ensuing treaty of peace. In no case shall they be sold or given away, if captured by the armies of the United States, nor shall they ever be privately appropriated, or wantonly destroyed or injured."

12 Merryman Free Movement, supra nota 11, p. 3.

13 Regulations to the Convention Concerning Laws and Customs of War on Land, Oct. 18 , 1907, arts. 27, 56, 36 Stat. 2277 [daqui para diante Haia IV]; Convention Concerning Bombardment by Naval Forces in Time of War, Oct. 18, 1907, art. 5, 36 Stat. 2351 [daqui para diante Haia IX]. 
em Haia em 1907, convocado conjuntamente pela Rússia e pelos Estados Unidos, resultou na produção de uma série de regras internacionais para a conduta de guerra. ${ }^{14} \mathrm{O}$ artigo $56 \mathrm{da}$ IV Convenção (sobre as leis e os costumes de guerra terrestre) e o artigo $5^{\circ}$ da IX Convenção (sobre os bombardeios navais) estabelecem o dever dos habitantes das povoações sitiadas ou atacadas de protegerem as edificações dedicadas à religião, à arte e à ciência, através da indicação da presença de tais edificações com sinais distintivos e visíveis. ${ }^{15}$ Aliás, a IV Convenção proíbe a destruição da propriedade do inimigo, a não ser que tal destruição seja imperativamente necessária, e proíbe qualquer confisco de obras de arte. ${ }^{16}$ De acordo com a IV Convenção, os indivíduos responsáveis por ofensas contra a propriedade cultural deveriam ser punidos pelas autoridades de suas nações de origem. ${ }^{17}$
Até depois do final da Segunda Guerra Mundial, a IV Convenção dè Haia de 1907 continuava sendo a principal legislação internacional, regulando o comportamento dos beligerantes. ${ }^{18}$ Os Regulamentos são muito extensos, com mecanismos mínimos de execução. Mas graças a esta generalidade, um número suficiente de Estados já aceitou seus dispositivos para que pudessem vir a ser considerados costume internacional. ${ }^{19}$ Infelizmente, no entanto, estas convenções não foram capazes de prevenir a devastação massiva de catedrais, igrejas, museus e bibliotecas que decorreu da Primeira Guerra Mundial. ${ }^{20}$

Na década de 1930, em virtude da enorme destruição ocasionada pela Primeira Guerra, a comunidade internacional começava a dar mais atenção à criação de uma convenção visando exclusivamente à proteção do patrimônio cultural durante a guerra. ${ }^{21} \mathrm{Em}$

14 Merryman Two Ways, supra nota 12, p. 834-35.

15 Haia IV, supra nota 16, art. 56; Haia IX, supra nota 16 , art. $5^{\circ}$.

16 Haia IV, supra nota 16, art. 56. O artigo 56 dispõe o seguinte: "The property of municipalities, that of institutions dedicated to religion, charity and education, the arts and sciences, even when State property, shall be treated as private property. All seizure of, destruction or willful damage done to institutions of this character, historic monuments, works of art and science is forbidden, and should be made the subject of legal proceedings." 17 Id.

18 Merryman Two Ways, supra nota 12, p. 835.

19 David A. Meyer, The 1954 Hague Cultural Property Convention and its Emergence into Customary International Law, 11 B.U. INT'L L.J. 349, 354 (1993).

20 Birov, supra nota 9, p. 208-09.

21 Merryman Two Ways, supra nota 12, p. 835. 
1935, os países da América promulgaram a primeira destas convenções internacionais, comumente conhecida como Pacto Roerich. ${ }^{22}$ O Pacto determinava que as partes beligerantes tratassem os bens culturais "com respeito e proteção". ${ }^{23}$ Aliás, em 1939, os governos da Bélgica, da Espanha, dos Estados Unidos, da Grécia e da Holanda, através da Liga das Nações, promulgaram a minuta de uma Convenção Internacional para a Proteção dos Monumentos e as Obras de Arte em Tempos de Guerra. Não obstante, a iminente eclosão da Segunda Guerra Mundial, e o conceito nazista de "guerra total", somados às conseguintes ofensas sistemáticas contra os bens culturais, tornaram vãos quaisquer esforços contemporâneos ou anteriores para proteger o patrimônio cultural. ${ }^{24}$

\section{A Segunda Guerra e o \\ Tribunal de Nuremberg}

A Alemanha nazista efetuou o mais completo e sistemático saque de arte da História; Hitler já tinha promulgado um decreto em 1942, autorizando o confisco dos bens culturais dos judeus, assim como dos museus e das bibliotecas dos territórios ocupados. No final da Segunda Guerra, o Einsatzstab Rosenberg, agência encarregada do saque dos territórios vencidos, já tinha pilhado em torno de vinte e duas mil obras de arte da Europa Ocidental e devastado inúmeras coleções na União Soviética, dentre elas o Museu de Leon Tolstoy. ${ }^{25}$

O Tribunal de Nuremberg impulsionou a evolução da proteção internacional do patrimônio cultural, com o julgamento e a condenação de Alfred Rosenberg, o dirigente do Einsatzstab; Rosenberg foi enforcado por, entre outras, ofensas contra a propriedade cultural. ${ }^{26}$ Outros réus foram julgados por tribunais nacionais; um tribunal polonês, por exemplo, condenou o nazista Wilhelm Ernest Palazieux pela pilhagem de bens culturais poloneses. ${ }^{27}$ Os julgamentos que ocorreram em Nuremberg e nos tribunais nacionais, depois da Segunda Guerra, estabeleceram um precedente que seria muito influente: a partir de

22 Treaty on the Protection of Artistic and Scientific Institutions and Monuments (Roerich Pact), Apr. 15, 1935, 49 Stat. 3267, TS No. 899, 167 LNTS 279.

23 Id. art. 52.

24 Vide Merryman Two Ways, supra nota 12, p. 835.

25 Trial of the Major War Criminals Before the International Military Tribunal, Nuremberg, 14 November 1945 - 1 October 1946, International Military Tribunal, pp. 294, 259 (Nuremberg, 1948) [daqui para diante Nuremberg]. Vide também Birov, supra nota 9, pp. 210-11.

26 Nuremberg, supra nota 28, p. 296.

27 Birov, supra nota 9, p. 211. 
então, os indivíduós podiam ser responsabilizados penalmente pelo saque e pela destruição dos bens culturais. $^{28}$

\section{A Convenção de Haia de $\mathbf{1 9 5 4}$}

A destruição massiva que resultou dos bombardeios e dos saques realizados durante a Segunda Guerra Mundial acarretou a elaboração da Convenção para a Proteção de Bens Culturais em Caso de Conflito Armado de $1954 .{ }^{29}$ O primeiro acordo transcontinental visando exclusivamente à proteção do patrimônio cultural, a Convenção de Haia proíbe a pilhagem e a destruição da propriedade cultural na ausência de uma imperativa necessidade militar. ${ }^{30}$ A rationale por trás da criação da Convenção aparece na Exposição de Motivos: "Convencidas de que os danos causados aos bens culturais pertencentes a qualquer povo constituem um prejuizo ao patrimônio

28 Vide, e.g., Convenção para a Proteção de Bens Culturais em Caso de Conflito Armado, assinada na Conferência Internacional reunida em Haia, de 21 de abril a 12 de maio de 1954 , art. 28 [daqui para diante Haia 1954]: "As Altas Partes Contratantes comprometem-se a tomar, no quadro de seus sistemas de direito penal, todas as medidas necessárias para descobrir e castigar com sanções penais ou disciplinares as pessoas, qualquer que seja a nacionalidade das mesmas que tenham cometido ou ordenado que se cometesse uma infração à presente Convenção." Vide também Estatuto do Tribunal Penal Internacional para a ex-lugoslávia, adotado em 25 de maio de 1993, pela Resolução 827 do Conselho de Segurança, disponivel em http://www.un.org/icty/legaldoc/index.htm, art. $3^{\circ}(\mathrm{d})$. Vide também Birov, supra nota 9, p. 211.

29 Haia 1954, supra nota 31 ü A Convenção de Haia foi aprovada no Brasil, com o texto integral em português, pelo Decreto Legislativo n. 32, de 1956; foi promulgada pelo Decreto n. 44.851, de 11 de novembro de 1958.

30 Haia 1954, supra nota 31 , art. $4^{\circ}$ (1). Os três principais parágrafos dispondo sobre os deveres dos Estados-partes seguem: Art. $4^{\circ}$ (1): “As Altas Partes Contratantes comprometem-se a respeitar os bens culturais situados, tanto em seu próprio território, quanto no território das outras Altas Partes Contratantes, abstendo-se de utilizar esses bens, seus sistemas de proteção e suas redondezas para fins que possam expor tais bens à destruição ou deterioração em casos de conflito armado e privando-se de todo ato de hostilidade para com esses bens." Art. $4^{\circ}$ (2): "As obrigações definidas no parágrafo primeiro do presente artigo só poderão deixar de ser cumpridas quando uma necessidade militar impedir de maneira imperativa o seu cumprimento." (ênfase acrescentada) Art. $4^{\circ}$ (3): "As Altas Partes Contratantes comprometem-se, outrossim, a proibir, a impedir e a fazer cessar, quando necessário, qualquer ato de roubo, de pilhagem e de apropriação indevida de bens culturais, qualquer que seja a forma de que venham revestidos esses atos, e, igualmente, todos os atos de vandalismo para com os bens mencionados. Comprometem-se também a não requisitar bens culturais móveis situados no território de outra Alta Parte Contratante." 
cultural de toda a humanidade, dado que cada povo traz a sua própria contribuição à cultura mundial...."

A Convenção de Haia proporciona uma proteção bem mais abrangente do que as precedentes. Embora se restrinja somente às ações das forças armadas durante a guerra, aplica-se a todos os conflitos armados e às ocupações bélicas de qualquer natureza, mesmo que seja um conflito puramente interno. ${ }^{32}$ Aliás, a Convenção fornece uma definição bastante ampla de "bens culturais", incluindo os monumentos de arquitetura, as obras de arte, os manuscritos, os livros de interesse histórico, os museus, as grandes bibliotecas, os depósitos de arquivos, os sítios arqueológicos e os edifícios históricos. ${ }^{33}$

A Convenção estabelece dois deveres principais para os Estados- partes cumprirem. Em primeiro lugar, as partes são obrigadas a respeitar os bens culturais situados tanto em seu próprio território, quanto no território do inimigo; não é permitido usar tais bens para fins que possam expô-los à destruição, que inclui o bombardeio e a requisição. ${ }^{34}$ Além disso, as partes contratantes têm a responsabilidade de proteger os bens; isto é, de proibir e de impedir que ocorra "qualquer ato de roubo, de pilhagem e de apropriação indevida de bens culturais", inclusive os atos de vandalismo. ${ }^{35} \mathrm{O}$ Protocolo da Convenção aplica-se aos territórios ocupados, obrigando as forças no controle a impedir a exportação dos bens culturais. ${ }^{36}$

Seguindo o precedente estabelecido pelo Tribunal de Nuremberg, a Convenção prevê um tipo de sanção para o descumprimento de seus dispositivos: o

\section{Id., Exposição de Motivos.}

32 Id. arts. $18^{\circ}(1), 18^{\circ}(2)$ e $19^{\circ}(1)$. O texto destes artigos segue: Art. $18^{\circ}$ (1): "Com exceção das disposições que devem entrar em vigor em tempo de paz, a presente Convenção será aplicada em caso de guerra declarada, ou de qualquer outro conflito armado que possa surgir entre duas ou mais das Altas Partes Contratantes, mesmo quando qualquer delas não reconheça o estado de guerra." Art. $18^{\circ}$ (2): "A Convenção será aplicada igualmente em todos os casos de ocupação inteira ou parcial do território de uma Alta Parte Contratante, mesmo quando essa ocupação não encontrar nenhuma resistência militar." Art. $19^{\circ}$ (1): "Em caso de conflito armado que não tenha caráter internacional e que tenha surgido no território de uma das Altas Partes Contratantes, cada uma das Partes em conflito ficará obrigada a aplicar, pelo menos, as disposições desta Convenção relativas ao respeito dos bens culturais."

$33 I d$ arts. $1^{\circ}$ (a)-(c).

34 Id. $\operatorname{art} .4^{\circ}(1)$.

35 Id. $\operatorname{art} .4^{\circ}(3)$.

36 Protocol for the Protection of Cultural Property in the Event of Armed Conflict, May 14, 1954, 249 U.N.T.S. 358 (1954), §§ 1-3. 
castigo com sanções penais de quaisquer pessoas de qualquer nacionalidade "que tenham cometido ou ordenado que se cometesse uma infração" ao tratado. ${ }^{37}$ Esta linguagem parece autorizar e até obrigar os países em cujo território se encontram violadores a processar penalmente estas pessoas. ${ }^{38}$

A ampla proteção proporcionada pela Convenção de 1954 aos bens culturais, no entanto, é limitada em um importante aspecto: o artigo $4^{\circ}(2)$ prescreve que as obrigações de salvaguardar os bens culturais "poderão deixar de ser cumpridas quando uma necessidade militar impedir de maneira imperativa o seu cumprimento". ${ }^{39}$ Isto significa dizer que a necessidade militar pode justificar a destruição dos bens culturais que normalmente seriam protegidos. Um exemplo clássico é o bombardeio de uma igreja que se encontrava ao lado de uma fábrica de munições. Ainda que a Convenção não defina as fronteiras da "necessidade militar" - o que tem gerado muita polêmica desde 1954 -, um dispositivo análogo do Código Lieber ilumina o debate: " $A$ necessidade militar... consiste na necessidade de todas as medidas que são indispensáveis para assegurar os fins da guerra..." "40 A exceção da necessidade militar, discutida em mais detalhes abaixo, constitui, talvez, a maior fraqueza da Convenção de Haia.

A Convenção de Haia de 1954 e seu Protocolo continuam sendo os únicos instrumentos mundiais dedicados exclusivamente à proteção dos bens culturais durante o conflito armado. ${ }^{41}$ Em março de 2003, eram 105 Estadospartes ao tratado. ${ }^{42}$

\section{As convenções de Genebra $e$ seus protocolos}

As Convenções de Genebra de 1949 , principais instrumentos estabelecendo as regras que regulam a condução da guerra em geral, não

37 Haia 1954, supra nota 30, art. 28.

38 Merryman Two Ways, supra nota 12, p. 836.

39 Haia 1954 , supra nota 31 , art. $4^{\circ}(2)$.

40 Código Lieber, supra nota 13, art. 14. O artigo 14 dispõe o seguinte: "Military necessity, as understood by modern civilized nations, consists in the necessity of those measures which are indispensable for securing the ends of war, and which are lawful according to the modern law and usages of war."

41 Birov, supra nota 9, p. 218.

42 Vide UNESCO, Convention and First Protocol for the Protection of Cultural Property in the Event of Armed Conflict (The Hague, 14 May 1954), List of the 105 States Parties, em http://www.unesco.org/ culture/laws/hague/html_eng/page9.shtml. 
contêm dispositivos específicos sobre a proteção da propriedade cultural. Em 1978, no entanto, quando a comunidade internacional se reuniu para renovar e atualizar as Convenções de Genebra, os delegados se detiveram especificamente no tema da preservação dos bens culturais. ${ }^{43}$ O princípio fundamental que ao final foi resguardado nos Protocolos é o seguinte: os beligerantes devem distinguir entre os objetos civis e os objetos militares, e devem dirigir suas ações militares só contra estes últimos. ${ }^{44}$ Em termos específicos, os Protocolos proíbem "quaisquer atos de hostilidade cometidos contra os monumentos históricos, as obras de arte ou o patrimônio cultural ou espiritual dos povos. "45 Embora os Protocolos de Genebra não trouxessem inovações ao corpo jurídico internacional protetor dos bens culturais, ajudaram a ampliar e fortalecer o princípio segundo o qual o desrespeito ao patrimônio cultural constitui um crime de guerra. ${ }^{46}$

\section{Os estatutos dos tribunais penais internacionais}

Apesar do novo marco normativo do pós-guerra proibir os ataques contra os bens culturais, a destruição do patrimônio cultural, durante a prolongada guerra na ex-Iugoslávia, assumiu uma forma particularmente brutal: as campanhas sérvias de limpeza étnica incluíam como tática essencial a destruição e a pilhagem dos objetos e dos monumentos culturais dos povos alvos, visando assim a apagar qualquer lembrança histórica destas comunidades. ${ }^{47}$ O Conselho de Segurança da ONU, quando constituiu o Tribunal Penal Internacional para a exIugoslávia, incluiu os crimes de pilhagem e de destruição dos bens culturais no artigo $3^{\circ}(\mathrm{d})$ do Estatuto; dentre as violações das leis e dos costumes de guerra se encontram "o confisco, a destruição ou o dano intencional às instituições dedicadas à religião, à caridade e à educação, às artes e às ciências, aos monu-

\section{Birov, supra nota 9, p. 219.}

44 Protocol Additional to the Geneva Conventions of 12 August 1949, and Relating to the Protection of Victims of International Armed Conflicts (Protocol I), opened for signature Dec. 12, 1977, art. 56, 1125 U.N.T.S. 3 [daqui para diante Protocolo I de 1977]; Protocol Additional to the Geneva Conventions of 12 August 1949, and Relating to the Protection of Victims of Non-International Armed Conflicts (Protocol II), opened for signature Dec. 12, 1977, art. 16, 1125 U.N.T.S. 609 [daqui para diante Protocolo II de 1977].

45 Protocolo I, supra nota 47, art. 56; Protocolo II, supra nota 47, art. 16.

46 Birov, supra nota 9, p. 220.

47 Id. 
mentos históricos e às obras de arte e ciência "48 No caso "Bósnia Herzegovina", atualmente tramitando perante a Câmara de Primeira Instância, os réus Radovan Karadzic e Ratko Mladic estão sendo processados, entre outros crimes, pela destruição a instituições dedicadas à religião, sob o artigo $3^{\circ}$ (d) do Estatuto..$^{49}$ O Estatuto do novo Tribunal Penal Internacional também reconhece os ataques contra o patrimônio cultural como crime de guerra. ${ }^{50}$

\section{b) O desenvolvimento histórico da proibição de danos ao patrimônio cultural durante tempos de paz \\ O processo da construção de um regime jurídico internacional que visa a}

proteger o patrimônio cultural em tempos de paz desenvolveu-se independentemente do processo análogo para tempos de guerra, e é muito mais recente, começando a sério apenas em 1970, com a promulgação da Convenção da UNESCO. ${ }^{51} \mathrm{~A}$ diferença central entre os dois regimes é a de que os instrumentos para tempos de guerra aplicam-se somente à conduta das forças armadas, enquanto os instrumentos para tempos de paz também regulam a conduta de agentes privados. Outra diferença fundamental é a de que os instrumentos para tempos de paz se concentram principalmente no comércio dos bens culturais, enquanto os instrumentos para tempos de guerra também protegem a sua integridade física.

48 Estatuto do Tribunal Penal Internacional para a ex-Iugoslávia, supra nota 31 , art. $3^{\circ}$ (d) (tradução livre). $\mathrm{O}$ artigo $3^{\circ}$ (d) dispõe: "The International Tribunal shall have the power to prosecute persons violating the laws or customs of war. Such violations shall include, but not be limited to: ... (d) seizure of, destruction or wilful damage done to institutions dedicated to religion, charity and education, the arts and sciences, historic monuments and works of art and science..."

49 Vide Indictment, Prosecutor v. Kradzic e Mladic, ICTY Case No. IT-95-5-I, Count 6, disponível em $\mathrm{http} / / \mathrm{www} . u n . o r g / i c t y /$ indictment/english/kar-ii950724e.htm.

50 Estatuto de Roma do Tribunal Penal Internacional, aprovado em 17 de julho de 1998, art. $8^{\circ}(2)$. O artigo $8^{\circ}(2)$ dispõe: "A los efectos del presente Estatuto, se entiende por 'crímenes de guerra' ... (b) violaciones graves de las leyes y usos aplicables en los conflictos armados internacionales dentro del marco establecido de derecho internacional, a saber, cualquiera de los actos siguientes: (ix) [d]irigir intencionalmente ataques contra edificios dedicados a la religión, la educación, las artes, las ciencias o la beneficencia, los monumentos históricos ...." O Estatuto de Roma foi aprovado no Brasil pelo Decreto Legislativo n. 112, de 2002. 51 Convenção sobre as Medidas a Serem Adotadas para Proibir e Impedir a Importação, Exportação e Transferência de Propriedade Ilícita dos Bens Culturais, aprovada pela XVI Sessão da Conferência Geral da Organização das Nações Unidas para a Educação, a Ciência e a Cultura (UNESCO), realizada em Paris, de 12 de outubro a 14 de novembro de 1970 [daqui para diante UNESCO 1970]. A Convenção foi aprovada no Brasil, com o texto integral em português, pelo Decreto Legislativo n. 71, de 1972. Vide também Birov, supra nota 9, p. 221. 
1. A Convenção da UNESCO de 1970

O primeiro e principal instrumento internacional que visa a proteger os bens culturais em tempos de paz é a Convenção da UNESCO sobre as
Medidas a Serem Adotadas para Proibir e Impedir a Importação, Exportação e Transferência de Propriedade Ilícita dos Bens Culturais de 1970.52 A Convenção proíbe o contrabando de bens culturais furtados ou ilegalmente exportados. ${ }^{53}$

52 Id. Os instrumentos predecessores da Convenção da UNESCO são os seguintes: Resolução XIV, Proteção dos Monumentos Móveis, do $7^{\circ}$ Congresso Internacional de Estados Americanos de 1933; três minutas de convenções internacionais preparadas pela Liga das Nações em 1933, 1936 e 1939; e a Recomendação da UNESCO sobre as Medidas para Proibir e Impedir a Exportação, Importação e Transferência de Propriedade Ilícita dos Bens Culturais de 1964. Merryman Two Ways, supra nota 12, 842. Vide também Roger W. Mastalir, A Proposal for Protecting the "Cultural" and "Property" Aspects of Cultural Property Under International Law, 16 FoRDHAM INT'L L.J. 1033, 1053 (1992-93).

53 UNESCO 1970, supra nota 54, art. $3^{\circ}$ A definição dos bens culturais da Convenção da UNESCO é bem mais ampla do que a da Convenção de Haia de 1954. A definição se encontra no artigo $1^{\circ}$ : "Para os fins da presente Convenção, a expressão 'bens culturais' significa quaisquer bens que, por motivos religiosos ou profanos, tenham sido expressamente designados por cada Estado como de importância para a arqueologia, a pré-história, a história, a literatura, a arte ou a ciência e que pertençam às seguintes categorias:

a) as coleções e exemplares raros de zoologia, botânica, mineralogia e anatomia, e objetos de interesse paleontológico;

b) os bens relacionados com a história, inclusive a história da ciência e da tecnologia, com a história militar e social, com a vida dos grandes estadistas, pensadores, cientistas e artistas nacionais e com os acontecimentos de importância nacional;

c) o produto de escavações arqueologias (tanto as autoridades quanto as clandestinas) ou de descobertas arqueologias;

d) elementos procedentes do desmembramento de monumentos artísticos ou históricos e de lugares de interesse arqueológico;

e) antigüidades de mais de cem anos, tais como inscrições, moedas e selos gravados;

f) objetos de interesse etnológico;

g) os bens de interesse artístico, tais como:

(i) quadros, pinturas e desenhos feitos inteiramente a mão sobre qualquer suporte e em qualquer material (com exclusão dos desenhos industriais e dos artigos manufaturados a mão);

(ii) produções originais de arte estatuária e de escultura em qualquer material;

(iii) gravuras, estampas e litografias originais;

(iv) conjuntos e montagens artísticas em qualquer material;

h) manuscritos raros e incunábulos, livros, documentos e publicações antigos de interesse especial (histórico, artístico, científico, literário, etc.), isolados ou em coleções;

i) selos postais, fiscais ou análogos, isolados ou em coleções;

j) arquivos, inclusive os fonográficos, fotográficos e cinematográficos;

k) peças de mobília de mais de cem anos e instrumentos musicais antigos." 
Qualquer exportação ou transferência de propriedade que contraria as leis do país de origem denomina-se "ilícita" sob o artigo $3^{\circ} ; 54$ os Estadospartes se comprometem a prevenir a importação de tais bens e a ajudar a sua repatriação. ${ }^{55}$ Para esses fins, a Convenção estabelece mecanismos para que um Estado-parte possa entrar em pactos bilaterais para reconhecer e executar as leis nacionais de outro Estado-parte. ${ }^{56}$ As partes também se comprometem a tomar as medidas necessárias para impedir que os museus nacionais adquiram bens culturais ilegalmente exportados. ${ }^{57}$

A rationale que inspirou a Convenção encontra-se na sua Exposição de Motivos: "Considerando que os bens culturais constituem um dos elementos básicos da civilização e da cultura dos povos, e que seu verdadeiro valor só pode ser apreciado quando se conhecem, com a maior precisão, sua origem, sua história e seu meio ambiente.... ",58 Os autores do tratado preocupavam-se majoritariamente com a difundida remoção dos bens culturais de países de poucos recursos econômicos para um pequeno grupo de países ricos aquisitivos, para ocuparem seus museus e suas coleções privadas. ${ }^{59}$ Outra preocupação importante era com a descontextualização da propriedade cultural: as escavações clandestinas privam de informações arqueológicas e etnológicas tanto o objeto furtado, quanto o lugar de onde foi tirado; estas informações teriam sido preservadas, caso a escavação tivesse sido supervisionada e documentada. ${ }^{60}$

Em julho de 2003, a Convenção da UNESCO de 1970 contava com a participação de 100 Estados-partes. Dentre eles, a maior parte são países fontes de bens culturais; até muito recentemente, unicamente os Estados Unidos, o Canadá e a Austrália podiam ser considerados países importadores de bens culturais. Esta falta de participação ativa na Convenção, por parte de muitos países importadores, inclusive o Japão e toda a Europa Ocidental, tem constituído uma das maiores fraquezas do tratado, tema discutido em mais detalhes abaixo. ${ }^{61}$

$54 \mathrm{Id}$ art. $3^{\circ}$.

$55 \mathrm{Id}$ art. $2^{\circ}(2)$.

$56 I d$. arts. $9^{\circ}, 13$ e 15.

$57 \mathrm{Id}$. art. $7^{\circ}(1)$.

58 ld., Exposição de Motivos.

59 Mastalir, supra nota 55, p. 1054.

60 Merryman Two Ways, supra nota 12, p. 843.

61 Forbes, supra nota 3, p. 240. 
2. A Convenção da UNESCO de 1972

A Convenção da UNESCO Relativa à Proteção do Patrimônio Mundial, Cultural e Natural foi adotada em 1972, para suplementar a Convenção da UNESCO de $1970 .{ }^{62}$ Estabelece um sistema de cooperação internacional para apoiar as partes, especialmente aquelas de recursos limitados, a conservar e identificar o seu patrimônio cultural e natural. ${ }^{63}$ Ademais, determina a criação de um inventário internacional dos bens do patrimônio cultural e natural de especial importância. ${ }^{64}$

\section{A Convenção da UNIDROIT de 1995}

A Convenção da UNIDROIT sobre Bens Culturais Furtados ou Ilicitamente Exportados, promulgada pelo Instituto Internacional para a Unificação do Direito Privado, em 1995, busca adiantar o propósito da Convenção da UNESCO de 1970, de regular o comércio transnacional de bens culturais. ${ }^{65}$ Os autores da Convenção reconheciam a continuidade e a persistência do tráfico ilegal e a pilhagem de sítios arqueológicos, por causa da ineficácia da Convenção da UNESCO, e resolveram assim fortalecer o regime de proteção. ${ }^{66}$

A Convenção da UNIDROIT estabelece uma via jurídica para a efetiva restituição, a partir da data da sua entrada em vigor, ${ }^{67}$ dos bens culturais ilegalmente exportados, através do mecanismo da carta rogatória. O tribunal de um Estado-parte pode requerer a um tribunal de outro Estado-parte o retorno de bens culturais ilicitamente exportados de seu território; ${ }^{68}$ o requerente deve estabelecer que tal exportação representou um prejuízo significativo à conservação material do bem, à sua integridade, ao seu uso tradicional ou ritual por parte de uma comunidade autóctone ou tribal, ou que o bem possui uma "importância cultural significativa" para o país. ${ }^{69}$

62 Convenção Relativa à Proteção do Patrimônio Mundial, Cultural e Natural, aprovado pela Conferência Geral da UNESCO, em sua XVII sessão, realizada em Paris, de 17 de outubro a 21 de novembro de 1972. A Convenção foi aprovada no Brasil, com o texto integral em português, pelo Decreto Legislativo n. 74, de 1977.

$63 \mathrm{Id}$. art. $5^{\circ}$.

64 Id. art. 11.

65 UNIDROIT 1995, supra nota 3, art. $1^{\circ}$ (a)-(b). Guruswamy, supra nota 5, p. 727.

66 Marilyn E. Phelan, The UNIDROIT Convention on Stolen or Illegally Exported Cultural Objects Confirms a Separate Property Status for Cultural Treasures, 5 VILL. SPORTs \& ENT. L.J. 31, 36-37 (1998). Vide também UNIDROIT 1995, supra nota 3, Exposição de Motivos. 67 Id. art. $10(1)$.

68 Id. art. $5^{\circ}(1)$.

$69 I d$ art. $5^{\circ}(3)(\mathrm{a})-(\mathrm{d})$. 
A obrigação do possuidor de bens furtados, ao invés do possuidor de bens meramente exportados ilegalmente, é mais clara e direta: "O possuidor de um bem cultural furtado deve restituilo. " 70 De acordo com o artigo $3^{\circ}(2)$, um bem cultural obtido através de escavações ilícitas, tanto como um bem licitamente obtido através de escavações, mas ilicitamente retido, considerase furtado. ${ }^{71}$ Além disso, enquanto a proteção conferida pela Convenção da UNESCO limita-se aos bens furtados que fazem parte do inventário de um museu ou de um monumento público, ${ }^{72}$ a Convenção da UNIDROIT estende a sua proteção a qualquer furto de bens culturais. Portanto, os bens furtados de particulares ou de coleções privadas, embora não tenham nenhum registro oficial, podem ser reclamados pelos seus proprietários originais. $^{73}$

Outra inovação importante da Convenção da UNIDROIT é a introdução da possibilidade de indenização para o comprador de boa-fé. ${ }^{74}$ Esta foi uma concessão aos países romanogermânicos, cujas leis reconhecem o direito de titularidade para o sujeito que comprou um objeto sem saber que fora furtado. ${ }^{75}$ Deste modo, enquanto o mandado da restituição dos bens furtados permaneça absoluto, ${ }^{76} \mathrm{o}$ artigo $4^{\circ}$ confere o pagamento de uma indenização eqüitativa ao possuidor que não sabia, ou não devia razoavelmente saber que o bem era furtado, e que pode provar "ter procedido às diligências cabiveis no momento da aquisição. "77 As partes têm que fazer "esforços razoáveis" para que a pessoa que transferiu o bem ao possuidor - seja o saqueador, o contrabandista ou um intermediário - pague a indenização; ${ }^{78}$ se não conseguirem achar pelo menos um dos autores conscientes do delito, o solicitante terá que arcar com o custo da indenização. ${ }^{79}$

Conforme $o$ artigo 12, a Convenção entrou em vigor no dia $1^{\circ}$ de julho de 1998. ${ }^{80}$ Em julho de 2003, dezoito países, na sua maioria países

70 Id. art. $3^{\circ}(1)$.

71 Id. art. $3^{\circ}(2)$.

72 UNESCO 1970, supra nota 54 , art. $7^{\circ}$ (b)(i).

73 Vide Forbes, supra nota 3, p. 246-47.

74 Guruswamy, supra nota 5, p. 728.

75 Forbes, supra nota 3, p. 247.

76 UNIDROIT 1995, supra nota 3 , art. $3^{\circ}(1)$.

$77 \mathrm{Id}$. art. $4^{\circ}(1)$.

78 Id. art. $4^{\circ}(2)$.

79 Id. art. $4^{\circ}(3)$.

80 Id. art. 12; Guruswamy, supra nota 5, p. 727. 
exportadores de bens culturais, já a tinham ratificado. ${ }^{81}$

\section{A INSUFICIENTE PROTEÇÃO DO PATRIMÔNIO CULTURAL PELO REGIME INTERNACIONAL}

Apesar da enorme ampliação, a partir do fim da Segunda Guerra Mundial, da rede de instrumentos jurídicos internacionais que visam a salvaguardar os bens culturais, dois fatos recentes bastam para evidenciar a contínua ineficácia do regime de proteção. Na ex-Iugoslávia, durante a década de 1990, os dispositivos da Convenção de Haia foram deliberada, sistemática e flagrantemente violados durante o que chegou a ser uma guerra cultural. Além disso, apesar da multiplicidade de esforços, desde 1970, para frear o tráfico ilícito de bens culturais, o comércio destes, furtados ou ilegalmente exportados, constitui uma das indústrias mais vantajosas no mundo contemporâneo, superado em termos de lucro só pelo narcotráfico. ${ }^{82}$ Esta Parte discutirá os aspectos dos três tratados internacionais principais, a Convenção de Haia de 1954, a
Convenção da UNESCO de 1970 e a Convenção da UNIDROIT de 1995, que têm permitido ou provocado a permanência da fragilidade do regime.

\section{A) A ineficácia da Convenção de Haia de 1954}

A fraqueza mais evidente da Convenção de Haia de 1954 é a qualificação da proteção pelo conceito da necessidade militar; uma imperativa necessidade militar justifica a destruição de bens culturais que normalmente desfrutariam de proteção. ${ }^{83} \mathrm{Em}$ primeiro lugar, como a Convenção não tem nenhum dispositivo que defina "necessidade militar", ou que estipule as circunstâncias que justificariam a invocação da doutrina, os comandantes militares freqüentemente substituem a palavra "necessidade" pela palavra "conveniência", uma vez que se encontram no campo de batalha. Por dar o direito de definir ao comandante (homem que talvez não consiga apreciar a significância de certos sítios culturais, ou que não tenha tempo suficiente para tomar uma decisão racional), a Convenção, assim, fica sujeita à arbitrariedade em sua interpretação. ${ }^{84}$ Ademais, na prática, os comandantes

81 Em julho de 2003, a Convenção contava com dezoito Estados-partes: Lituânia, Paraguai, Romênia, Peru, Hungria, Bolívia, Finlândia, Itália, Croácia, Camboja, Portugal, China, Equador, Brasil, El Salvador, Argentina, Noruega e Espanha. Vide http://www.unidroit.org/ english/implement/i-95.htm para a lista de Estados-partes e a data de ratificação ou adesão de cada um.

82 Forbes, supra nota 3, p. 238.

83 Haia 1954 , art. $4^{\circ}(2)$.

84 Birov, supra nota 9, p. 243-44. 
consideram outros valores, como a proteção à vida e à saúde das suas tropas, acima da proteção do patrimônio cultural, validando tal hierarquia com a invocação da "necessidade". ${ }^{85}$ Assim, "o patrimônio cultural de toda a humanidade" é posto à mercê dos interesses paroquiais de certos beligerantes. ${ }^{86}$

Outro aspecto que diminui a eficácia da Convenção de Haia é a falta de sanções autônomas e automáticas para os que transgridem os seus dispositivos; não existe nenhum organismo internacional independente para executar o tratado e punir os infratores. A única menção a sanções é encontrada no artigo 28 , que estabelece o dever de cada país de processar penalmente os violadores que se encontrem no seu território. ${ }^{87}$ Ademais, o número de Estados-partes da Convenção, apesar das quase cinco décadas de sua existência, é relativamente baixo; dentre os membros permanentes do Conselho de Segurança da ONU, apenas a França e a Rússia já ratificaram a Convenção de Haia. ${ }^{88}$

\section{B) A ineficácia da Convenção da UNESCO de 1970}

O maior defeito da Convenção da UNESCO, já mencionado acima, tem sido a falta de participação no tratado, até muito recentemente, por parte da maioria dos países importadores de bens

85 Merryman Two Ways, supra nota 12, p. 838. Enquanto os comandantes militares, quando têm que decidir entre a destruição de um monumento cultural e a segurança das suas tropas, quase invariavelmente optam por destruir o monumento, a atitude de Sir Harold Nicolson é interessante: "Não estou entre aqueles que sentem que os sítios religiosos têm mais importância do que as vidas humanas ...; nem hesitaria, se eu fosse comandante militar, a destruir algum prédio de significação puramente histórica se eu achasse que assim poderia assegurar uma vantagem tática ou diminuir o perigo para os meus homens. As obras de enorme valor artístico, no entanto, estão em uma categoria completamente diferente. Acho que é absolutamente desejável que tais obras sejam preservadas da destruição, mesmo que a sua preservação envolva o sacrifício de vidas humanas. Certamente eu estaria preparado para tomar um tiro na cabeça se tivesse certeza de que por tal sacrifício eu poderia preservar os afrescos de Giotto; de igual forma, não hesitaria por um instante ... a salvar a Catedral de São Marcos, mesmo sabendo que assim asseguraria a morte dos meus filhos... Minha atitude se governaria por um principio que é, sem dúvida, incontroverso. O insubstituível é mais importante do que o substituível, e a perda até da vida humana mais valiosa é ultimamente menos desastrosa do que a perda de algo que em nenhuma circunstância pode ser criado de novo." Id. p. 840 (tradução livre).

86 Vide Haia 1954, supra nota 31, Exposição de Motivos.

$87 \mathrm{Id}$. art. 28.

88 Birov, supra nota 9, p. 228. Os Estados Unidos se recusaram a ratificar o tratado porque, dentre outras razões, limitaria as suas opções, se eclodisse uma guerra nuclear. Id. 
culturais. ${ }^{89}$ Os Estados importadores que não ratificaram citam várias razões por sua oposição ao tratado. Em primeiro lugar, diversos países da União Européia alegam que a Convenção é incompatível com certos regulamentos de mercado da Comunidade Européia. Ademais, muitos temem que, por ratificar o tratado, seriam pressionados a repatriar os bens culturais previamente adquiridos, que por muito tempo estão expostos tranqüilamente nos seus museus. Depois de séculos de guerras nas quais o saque era perfeitamente permitido e até encorajado, as coleções européias de bens culturais estrangeiros não são insignificantes. Outrossim, parece haver uma certa falta de incentivo para os Estados ricos se ligarem ao tratado, porque já estabeleceram seus próprios sistemas efetivos para a proteção dos seus bens culturais nacionais. ${ }^{90}$ Até 1997, das grandes economias de mercado, somente os Estados Unidos, o Canadá e a Austrália tinham ratificado a Convenção; ${ }^{91}$ há nova razão para o otimismo, no entanto, com as recentes ratificações da França, do Japão e do Reino Unido. ${ }^{92}$

Sob a Convenção da UNESCO, apenas o Estado é dotado com a capacidade de designar quais dos bens culturais no seu território receberão a proteção conferida pelo tratado..$^{93}$ Este enfoque exclusivo no vínculo entre $o$ Estado e o patrimônio cultural nega aos povos indígenas e a outros grupos étnicos a habilidade de designar os bens com os quais eles se associam ou que consideram sagrados..$^{94}$ Como resulta-

89 Guruswamy, supra nota 5, p. 726-27; vide também Lehman, supra nota 7, p. 540. A Convenção foi implementada nos Estados Unidos pela Convention on Cultural Property, 19 U.S.C. S 2601 e no Canadá pela Cultural Property Export and Import Act, S.C., ch. 50, S 31(2) (1975).

90 Jason C. Roberts, The Protection of Indigenous Populations' Cultural Property in Peru, Mexico and the United States, 4 Tulsa J. Comp. \& InT'L L. 327, 336, 338 (1997).

91 Guruswamy, supra nota 5, p. 726-27. A Convenção foi implementada nos Estados Unidos pela Convention on Cultural Property, 19 U.S.C. S 2601 e no Canadá pela Cultural Property Export and Import Act, S.C., ch. 50, S 31(2) (1975).

92 Vide UNESCO, Convention on the Means of Prohibiting and Preventing the Illicit Import, Export and Transfer of Ownership of Cultural Property (Paris, 14 November 1970), List of the 100 States Parties as of 27 June 2003, em http://www.unesco.org/culture/laws/ 1970/html_eng/page3.shtml. A França ratificou a Convenção em 1997; o Reino Unido e o Japão a ratificaram em 2002. A Alemanha ainda não a ratificou.

93 UNESCO 1970, supra nota 54, art. $1^{\circ}$ : "Para os fins da presente Convenção, a expressão 'bens culturais' significa quaisquer bens que, por motivos religiosos ou profanos, tenham sido expressamente designados por cada Estado como de importância para a arqueologia, a pré-história, a história, a literatura, a arte ou a ciência..." (ênfase minha).

94 Ana Sljivic, Why Do You Think It's Yours? An Exposition of the Jurisprudence Underlying the Debate Between Cultural Nationalism and Cultural Internationalism, 31 GEO. WASH. J. INT'L L. \& ECON. 393, 398-99 (1997-98). Vide também Mastalir, supra nota 55, p. 1042. 
do, tem havido uma incompleta designação dos bens culturais, porque muitos países, deliberadamente ou por simples desatenção, ignoram o patrimônio cultural de suas comunidades indígenas. De igual maneira, a Convenção também nega à comunidade internacional o direito de designar os objetos merecedores de proteção. ${ }^{95}$

Um grupo de juristas, liderados pelo professor norte-americano John Merryman, tem feito outro tipo de crítica à Convenção da UNESCO: o tratado, por promover o que Merryman chama de "nacionalismo cultural", provoca uma situação na qual grandes quantidades de objetos com valor cultural mundial são "destrutivamente retidas" pelo país de origem..$^{96} \mathrm{O}$ Peru, por exemplo, retém uma abundância de bens culturais que não conserva adequadamente, nem exibe; se tais objetos fossem transferidos para um país com maiores recursos econômicos, poder-se-iam aproveitar dos museus e dos colecionadores que soubessem respeitá-los. Desta maneira, poderiam ser mais bem preservados e estudados, assim como vistos por maiores e mais diversos públicos; tal difusão, na qual os bens se tornam "embaixadores culturais", exibiria para o mundo as riquezas das culturas peruanas. ${ }^{97}$ Merryman sustenta que a melhor maneira para os bens culturais chegarem aos lugares mais capazes de os proteger é através do mercado; aqueles que estão dispostos a pagar o preço mais alto farão o necessário para preservar o seu investimento. A Convenção da UNESCO e as leis nacionais "cobiçosas" (ou egoístas) que ela encoraja, no entanto, opõem-se ao

95 Guruswamy, supra nota 5, p. 727-28.

96 Merryman Two Ways, supra nota 12, p. 846. Há, naturalmente, um grupo de juristas que se opõem a Merryman e aos outros "internacionalistas culturais", liderado por Roger Mastalir. Estes nacionalistas culturais apresentam vários argumentos, os principais dos quais aparecem a seguir, do ponto de vista dos direitos humanos para refutar as hipóteses dos internacionalistas: (1) quando há uma afinidade dos bens culturais com um grupo, aquele patrimônio cultural define e alimenta o grupo (e.g., a escultura Afo-A-Kom, de uma tribo da República de Camarões, dá força e segurança à tribo, mas só quando está fisicamente presente); (2) a importância cultural dos bens se diminui ou se destrói, e a cultura de onde provém se enfraquece, se os bens são afastados do seu contexto cultural; (3) portanto, os bens culturais devem ser estritamente inalienáveis para assegurar não só o valor dos mesmos, mas também a dignidade do grupo que lhes deu a sua origem: os elementos constitutivos de um grupo não se devem tornar bens fungíveis. Claro que esta linha de argumento tem maior força, quando os bens culturais podem ser reclamados por determinados e ainda existentes grupos étnicos dentro do país. Vide Mastalir, supra nota 55, p. 1046, 1062-63; vide também Sljivic, supra nota 97, p. 402; vide também John Moustakas, Group Rights In Cultural Property: Justifying Strict Inalienability, 74 CORNELL L. REv. 1179, 1205(1989).

97 Merryman Two Ways, supra nota 12, p. 846. Vide também Slijivic, supra nota 97, p. 415. 
mercado e, portanto, submetem os bens culturais ao descuido. ${ }^{98}$

\section{C) As perspectivas para a Convenção da UNIDROIT de 1995}

O período curto, durante o qual tem vigorado a Convenção da UNIDROIT, dificulta qualquer avaliação da sua eficácia na prevenção do tráfico ilícito de bens culturais. Não obstante, alguns aspectos do tratado permitem alguns prognósticos dos obstáculos com os quais o tratado terá que lidar.

Em primeiro lugar, parece haver uma persistência na oposição dos Estados importadores de bens culturais à ratificação do tratado. Embora alguns países da Europa Ocidental (a Itália, a Finlândia, a Noruega, a Espanha e Portugal) sejam partes da Convenção da UNIDROIT, o novo tratado ainda não conta com a participação do restante da Europa Ocidental, do Japão, dos Estados Unidos, do Canadá e da Austrália. ${ }^{99}$ Uma razão subjacente a tal oposição poderia ser a mesma que incentivou a falta de adesão de tantos países importadores à Convenção da
UNESCO: os países ricos já têm seus próprios sistemas eficazes para proteger os bens culturais nacionais. Afortunadamente, um dos argumentos em oposição à Convenção da UNESCO, segundo o qual os países não querem ser forçados a repatriar bens culturais adquiridos há muito tempo, não tem a mesma força nos debates sobre a ratificação da Convenção da UNIDROIT: os autores desta convenção, bem conscientes dos temores dos países importadores, estabeleceram uma série de prazos prescricionais dentro dos quais uma ação tem que ser iniciada. ${ }^{100}$

Outra grande dificuldade enfren-tada por este tratado emana da clássica dicotomia entre os países da common law e os países de tradição jurídica romanogermânica. Como se discutia acima, houve um debate entre os delegados durante o congresso que aprovou o texto da Convenção: os países romanogermânicos queriam proteger o comprador de boa-fé dos objetos furtados, enquanto os países da common law queriam uma regra de restituição absoluta dos bens ao proprietário original. ${ }^{101}$ O dispositiva que resultou deste debate

98 Merryman Two Ways, supra nota 12, p. 849.

99 Vide supra, nota 84 para a lista de Estados-partes da Convenção da UNIDROIT.

100 A Convenção estabelece três prazos de prescrição: (1) um prazo de três anos a partir do momento em que o solicitante toma conhecimento do lugar onde se encontra o bem cultural e da identidade do possuidor (art. $3^{\circ}(3)$ ); (2) um prazo máximo de cinqüenta anos a partir do momento do furto (art. $\left.3^{\circ}(3)\right)$; e (3) uma exceção para os bens que são essenciais para o patrimônio cultural de um Estado; em tal caso não há prazo de prescrição (art. $\left.3^{\circ}(4)\right)$. UNIDROIT 1995, supra nota 3, art. $3^{\circ}$ (3)-(4).

101 Vide Forbes, supra nota 3, p. 237. 
plenamente favorece os países da common law: "O possuidor de um bem cultural furtado deve restituilo. "102 Portanto, embora haja uma concessão no tratado, proporcionando uma indenização ao comprador de boafé, o artigo $3^{\circ}(1)$ poderia ainda ser inaceitável para aqueles países romano-germânicos que receiam que tal regra acarretaria incerteza nas relações comerciais. ${ }^{103}$

\section{PROPOSTAS PARA O MELHORAMENTO DO REGIME}

Em vista das múltiplas debilidades do regime atual de proteção internacional do patrimônio cultural, vários autores têm sugerido novas soluções para reforçá-lo, tanto durante os conflitos armados, quanto no âmbito do comércio e da preservação dos bens culturais em tempos de paz.

\section{A) Propostas para melhorar o regime de proteção do patri- mônio cultural durante a guerra}

Para o patrimônio cultural receber a proteção máxima possível, a exceção da necessidade militar tem que ser eliminada ou, pelo menos, circunscrita. Para conseguir tal circunscrição, um dispositivo deve ser acrescentado à Convenção de Haia de 1954, definindo com clareza os limites do termo e incorporando o princípio da proporcionalidade. ${ }^{104}$ Além disso, a decisão de quais situações concretas se constituem de necessidade militar deve ser tirada das mãos do "comandante militar" comum e colocada sob a competência exclusiva das autoridades mais altas.

Também, Charles McConney propõe a criação de uma unidade permanente dentro das forças de manutenção da paz da ONU, para proteger os monumentos e outros bens culturais durante os conflitos armados. ${ }^{105}$

102 UNIDROIT 1995, supra nota 3, art. $3^{\circ}$ (1).

103 Vide Forbes, supra nota 3, p. 237.

104 Durante a guerra, quando as forças de uma parte atacam um objetivo militar e há danos colaterais (isto é, civis feridos ou mortos ou danos a objetos não-militares), invoca-se o princípio da proporcionalidade. Conforme sua formulação no Protocolo I de 1977, os ataques são proibidos, se ocasionarem incidentalmente mortos e feridos entre a população civil, ou danos a bens de caráter civil, ou ambas as coisas, que seriam excessivos com relação à vantagem militar concreta e direta prevista. Desta forma, o princípio da proporcionalidade cria uma obrigação permanente para os comandantes militares compararem os resultados do ataque com a vantagem prevista. Horst Fischer, Principle of Proportionality, CRIMES OF WAR (Roy Gutman \& David Rieff eds., 1999). Vide também Protocolo I, supra nota 47, art. $5^{\circ}$ (b).

105 Charles E. McConney, Draft Proposal for the Creation of A Permanent Monuments, Fine Arts and Archives Unit Within the U.N. Peacekeeping Forces (1992), reimpressa em Patrick J. Boylan, Review of THE CONVENTION FOR THE PRotection of CUltural Property IN the Event of ARMed Conflict (1993), p. 200. 
Esta unidade seguiria o modelo das unidades M.F.A.\& A. (Monuments, Fine Arts \& Archives) da Segunda Guerra Mundial, que as Forças Aliadas estabeleceram em locais vulneráveis para impedir que as catedrais, os museus, as coleções de arte e os prédios históricos fossem saqueados. Da mesma maneira, as forças de paz da ONU poderiam assegurar zonas neutras em áreas de particular importância cultural. ${ }^{106}$

\section{B) Propostas para melhorar o regime de proteção dos bens culturais em tempos de paz}

Uma sugestão para robustecer o regime de proteção do patrimônio cultural em tempos de paz é a criação de um tribunal com competência específica para resolver os conflitos sobre o comércio dos bens culturais. ${ }^{107}$ Ann Prunty sustenta que o tribunal deve possuir o poder jurisdicional para acolher e determinar os conflitos sob as Convenções da UNESCO e da UNIDROIT, e quaisquer acordos bilaterais que existam entre as partes.
Após a entrega dos argumentos escritos de cada parte e uma audiência oral, o tribunal produziria um parecer escrito, explicando o seu raciocínio, assim contribuindo, com cada caso, para a criação de um crescente corpo de jurisprudência. ${ }^{108}$

Uma das principais críticas que John Merryman lança ao nacionalismo cultural é a de que os países fontes não têm a infraestrutura apropriada para preservar os bens culturais que se encontram no seu território. ${ }^{109}$ Roger Mastalir concebe uma solução análoga àquela que foi empregada para combater a destruição da camada de ozônio. Ao perceberem que as normas aplicáveis eram impossíveis de serem cumpridas pelos países subdesenvolvidos, os países desenvolvidos resolveram proporcionar a assistência necessária, através de transferência de tecnologia, de conhecimento técnico e de recursos econômicos. De igual maneira, sustenta Mastalir, poder-se-ia implementar um sistema de transferência de tecnologia para assegurar a

106 Id. p. 201. Vide também Birov, supra nota 9, p. 246.

107 A Convenção da UNESCO de 1970 trata o assunto da resolução de conflitos em apenas um dispositivo. O artigo 17 (5) dispõe o seguinte: "Mediante solicitação de, pelo menos, dois Estados-partes na presente Convenção que se achem envolvidos em uma controvérsia a respeito de sua implementação, a UNESCO poderá oferecer seus bons ofícios a fim de que seja alcançada uma composição entre eles." UNESCO 1970, supra nota 53, art. 17 (5). A Convenção não antecipa nenhum outro procedimento ou mecanismo para resolver os conflitos.

108 Vide Ann P. Prunty, Toward Establishing an International Tribunal for the Settlement of Cultural Property Disputes: How to Keep Greece from Losing Its Marbles, 72 Geo. L. J. 1155, 1167-82(1984).

109 Merryman Two Ways, supra nota 12, p. 846. 
proteção física dos bens culturais e promover a sua maior exibição ao público. ${ }^{110}$ Os países desenvolvidos teriam um incentivo para ajudar, por causa da resultante distribuição de bens culturais por meio de intercâmbios, empréstimos de longo prazo e exibições cooperativas. "'

Catherine Vernon recomenda outra solução para proteger os bens culturais ameaçados de furto, destruição ou deterioração, na forma de um direito de intervenção preventiva, por parte de organizações internacionais ou grupos de Estados, na soberania territorial dos países; ${ }^{112}$ os contornos de tal direito seriam modelados pela Convenção das Nações Unidas sobre o Direito do Mar. ${ }^{113}$ Esta convenção designa os objetos arqueológicos subaquáticos além do mar territorial de cada país como parte do patrimônio cultural da humanidade; a comunidade internacional goza de pleno acesso para estudar e proteger esses objetos. ${ }^{114}$ Alguns autores propõem uma expansão deste direito, na forma de uma nova norma que conceda autoridade limitada à comunidade internacional de intervir para preservar os sítios arqueológicos subaquáticos de particular importância, embora estes se encontrem dentro do mar territorial. ${ }^{115}$ Assim, ainda que o Estado costeiro mantenha o controle preferencial sobre aquela parte do mar, ele não seria exclusivo.

Por analogia, Vernon promove a extensão desta noção aos bens culturais na superfície terrestre. O Estado no qual os bens se situam permaneceria com seus direitos territoriais, sujeitos a um direito superior de intervenção da comunidade internacional, se não proteger suficientemente aqueles objetos que formam parte imprescindível do patrimônio cultural da humanidade. Esta classe de jurisdição extraterritorial se justificaria, já que a proteção inadequada dos bens culturais de valor

110 Mastalir, supra nota 55, p. 1074-77.

111 Id. p. 1081-82.

112 Vide M. Catherine Vernon, Common Cultural Property: The Search For Rights Of Protective Intervention, 26 CASE W. RES. J. INT'L L. 435, 440-45, 471-75 (1994).

113 Vide Convenção das Nações Unidas sobre o Direito do Mar, concluído em Montego Bay, Jamaica, em 10 de dezembro de 1982, U.N. Doc. A/CONF.62/122 (1982). A Convenção foi aprovada no Brasil pelo Decreto Legislativo n. 5, de 1987.

$114 \mathrm{O}$ artigo 149 dispõe: "[A]ll objects of an archaeological and historical nature found in the Area [beyond the twelve-mile national jurisdiction of coastal states] shall be preserved or disposed of for the benefit of mankind as a whole, particular regard being paid to the preferential rights of the States or Country of origin, or the State of cultural origin, or the State of historical and archaeological origin." Id art. 149. O mar territorial se estende por doze milhas náuticas da costa. Id arts. $3^{\circ}-4^{\circ}$.

115 Vernon, supra nota 115, p. 474. 
universal prejudica o interesse que todos os demais têm nesses bens. ${ }^{116}$

\section{CONCLUSÃO}

É preciso ser realista e reconhecer o triste fato de que alguns infratores das regras que visam a proteger o patrimônio cultural, apesar da natureza fundamental destas ou de qualquer universalidade que possam ter atingido, recusar-se-ão a cumprir tais normas, porque o proveito que tiram do continuado descumprimento é grande demais. No âmbito da guerra, embora os princípios subjacentes da Convenção de Haia já alcançassem o status de costume, o tratado ainda não era capaz de impedir a enorme aniquilação de bens culturais que o mundo testemunhou na década de 1990. ${ }^{117}$ Um dos obstáculos deveria ser óbvio: como disse o diretor de um museu na Bósnia, depois de tentar salvar algumas obras de arte de zonas de guerra sob controle sérvio, "ninguém se preocupa com a arte quando as pessoas estão morrendo". ${ }^{118}$ Isto é, as regras jurídicas raramente adiantam em ambientes de destruição sem limite, especialmente quando um dos objetivos centrais dos beligerantes é justamente apagar a identidade cultural do inimigo. Aliás, no contexto das transferências transnacionais dos bens culturais em tempos de paz, a enorme lucratividade do mercado encoraja o tráfico ilícito, dificultando assim qualquer tentativa jurídica de regular o comércio da propriedade cultural.

Mas apesar dos obstáculos que têm enfrentado os esforços internacionais para salvaguardar o patrimônio cultural, também há diversos fatores que estimulam o otimismo. Um destes fatores é o de que, atualmente, depois de decorridos noventa e um anos de adiantamentos jurídicos, desde os Regulamentos de Haia de 1907, até o Estatuto de Roma de 1998, o patrimônio cultural desfruta de uma posição inabalável naquilo que nos dedicamos a defender como comunidade global. Talvez o legado mais duradouro dos instrumentos jurídicos para tempos de guerra seja o desenvolvimento do conceito da responsabilidade penal individual e universal por ofensas cometidas contra o patrimônio cultural, que parece estar dando resultados positivos. ${ }^{119} \mathrm{Na}$ área da proteção durante tempos de paz, embora talvez

116 Id. p. 474-75.

117 Vide Meyer, supra nota 22, p. 351.

118 Birov, supra nota 9, p. 240. Esta hierarquia de facto aplica-se também aos comandantes militares; como mencionado acima, quase invariavelmente colocarão a segurança das suas tropas acima da proteção dos bens culturais, validando quaisquer danos aos bens com a invocação do conceito da necessidade militar. Merryman Two Ways, supra nota 12, p. 838. 119 Vide infra notas 50-53 acima, com texto correspondente. 
seja cedo demais para elogiar ou criticar a efetividade da Convenção da UNIDROIT, a recente onda de ratificações da Convenção da UNESCO de 1970, por parte de alguns dos países de

\section{BIBLIOGRAFIA}

\section{A) Artigos}

BIROV, Victoria A., Prize or Plunder?: The Pillage of Works of Art and the International Law of War, 30 New York UNIVERSITY JourNaL of International LaW \& Policy 201 (1997-98).

FISCHER, Horst, Principle of Proportionality, CRIMES OF WAR (Roy Gutman \& David Rieff eds., 1999).

FORBES, Stephanie O., Securing the Future of Our Past: Current Efforts to Protect Cultural Property, 9 TRANSNAT'L LaW 235 (1996).

GURUSWAMY, Lakshman, Jason C. Roberts and Catina Drywater, Protecting the Cultural and Natural Heritage: Finding Common Ground, 34 Tulsa LaW JouRnal 713 (1999).

LEHMAN, Jennifer H., The Continued Struggle with Stolen Cultural Property: The Hague Convention, the UNESCO Convention, and the UNIDROIT Draft Convention, 14 ARIZONA JOURNAL OF INTERNATIONAL \& Comparative Law 527 (1997). mercado mais significativos, pode assinalar, depois de tantas décadas de divergência, um novo consenso internacional quanto à repugnância do comércio ilícito dos bens culturais. ${ }^{120}$

MARINER, Joanne, Liberation and Looting in Iraq, FindLaW's LeGal Commentary, Apr. 14, 2003, em http://writ.news.findlaw.com/mariner/20030414.html.

MASTALIR, Roger W., A Proposal for Protecting the "Cultural" and "Property" Aspects of Cultural Property Under International Law, 16 FORDHAM INTERNATIONAL LaW JOURNaL 1033 (1992-93).

MERRYMAN, John Henry, Two Ways of Thinking About Cultural Property, 80 AMERICAN JOURNAL OF INTERNATIONAL LAW 831 (1986).

MERRYMAN, John Henry, The Free International Movement of Cultural Property, 31 NEW YORK UNIVERSITY JOURNAL OF INTERNATIONAL LaW \& Policy 1 (1998).

MEYER, David A., The 1954 Hague Cultural Property Convention and its Emergence into Customary International Law, 11 BostoN UNIVERSITY INTERNATIONAL LAW JOURNAL 349 (1993).

MOUSTAKAS, John, Group Rights In Cultural Property: Justifying

${ }^{120}$ Vide infra nota 95 acima, com texto correspondente. 
Strict Inalienability, 74 CORNELL

LAW REVIEW 1179 (1989).

OLIVEIRA, Helli Alves de, Responsabilidade pelos danos ao patrimônio cultural, 319 REVISTA FORENSE 49 (1992).

PHELAN, Marilyn E., The UNIDROIT Convention on Stolen or Illegally Exported Cultural Objects Confirms a Separate Property Status for Cultural Treasures, 5 Villanova Sports \& ENTERTAINMENT LAW JOURNAL 31 (1998).

PRUNTY, Ann P., Toward Establishing an International Tribunal for the Settlement of Cultural Property Disputes: How to Keep Greece from Losing Its Marbles, 72 GEORGETOWN LAW JoURNAL 1155 (1984).

ROBERTS, Jason C., The Protection of Indigenous Populations' Cultural Property in Peru, Mexico and the United States, 4 TULSA JOURNAL OF COMPARATIVE \& INTERNATIONAL LAW 327 (1997).

SLIJIVIC, Ana, Why Do You Think It's Yours? An Exposition of the Jurisprudence Underlying the Debate Between Cultural Nationalism and Cultural Internationalism, 31 GEORGE WASHINGTON JOURNAL OF INTERNATIONAL LAW \& ECONOMICS 393 (1997-98).

VERNON, M. Catherine, Common Cultural Property: The Search for Rights of Protective Intervention, 26 Case Western Reserve Journal of INTERNATIONAL LAW 435 (1994).

\section{B) Tratados internacionais}

Regulations to the Convention Concerning Laws and Customs of War on Land, Oct. 18, 1907, 36 Stat. 2277. Convention Concerning Bombardment by Naval Forces in Time of War, Oct. 18, 1907, Stat. 2351.

Treaty on the Protection of Artistic and Scientific Institutions and Monuments (Roerich Pact), Apr. 15, 1935, 49 Stat. 3267 , TS No. 899,167 LNTS 279.

Convenção para a Proteção de Bens Culturais em Caso de Conflito Armado, assinada na Conferência Internacional reunida em Haia, de 21 de abril a 12 de maio de 1954 .

Protocol for the Protection of Cultural Property in the Event of Armed Conflict, May 14, 1954, 249 U.N.T.S. 358 (1954).

Convenção Relativa à Proteção do Patrimônio Mundial, Cultural e Natural, aprovado pela Conferência Geral da UNESCO, em sua XVII sessão, realizada em Paris, de 17 de outubro a 21 de novembro de 1972. Convenção sobre as Medidas a Serem Adotadas para Proibir e Impedir a Importação, Exportação e Transferência de Propriedade Ilícita dos Bens Culturais, aprovada pela XVI Sessão da Conferência Geral da Organização das Nações Unidas para a Educação, a Ciência e a Cultura (UNESCO), realizada em Paris, de 12 de outubro a 14 de novembro de 1970.

Protocol Additional to the Geneva Conventions of 12 August 1949, and 
Relating to the Protection of Victims of International Armed Conflicts (Protocol I), opened for signature Dec. 12, 1977, 1125 U.N.T.S. 3.

Protocol Additional to the Geneva Conventions of 12 August 1949, and Relating to the Protection of Victims of Non-International Armed Conflicts (Protocol II), opened for signature Dec. 12, 1977, 1125 U.N.T.S. 609.

Convenção das Nações Unidas sobre o Direito do Mar, concluído em Montego Bay, Jamaica, em 10 de dezembro de 1982, U.N. Doc. A/ CONF. 62/122 (1982).

Convenção da UNIDROIT sobre Bens Culturais Furtados ou Ilicitamente Exportados, celebrada em Roma, no dia 24 de junho de 1995.

Estatuto de Roma do Tribunal Penal Internacional, aprovado em $17 \mathrm{de}$ julho de 1998.

\section{C) Outras fontes}

LIEBER, Francis, Instructions for the Government of Armies of the United States in the Field, reimpressa em THE MiscellaneOUS
Writings of Francis Lieber 247. Trial of the Major War Criminals Before the International Military Tribunal, Nuremberg, 14 November 1945 1 October 1946, International Military Tribunal, (Nuremberg, 1948).

Constituição da República Federativa do Brasil, promulgada em 5 de outubro de 1988, art. 216.

MCCONNEY, Charles E., Draft Proposal for the Creation of A Permanent Monuments, Fine Arts and Archives Unit Within the U.N. Peacekeeping Forces (1992), reimpressa em Patrick J. Boylan, ReView of THE CONVENTION FOR tHE Protection of Cultural Property in the Event of Armed Conflict (1993).

Estatuto do Tribunal Penal Internacional para a ex-Iugoslávia, adotado 25.05 .93 pela Resolução 827 do Conselho de Segurança, disponível em http://www.un.org/icty/legaldoc/ index.htm.

Indictment, Prosecutor v. Kradzic e Mladic, ICTY Case No. IT-95-5-I, Count 6, disponivel em http:// www.un.org/icty/indictment/ english/kar-ii950724e.htm. 